\title{
Analysis of Driving Forces of Energy Consumption in Rural Areas of China's Henan Province Based on the STIRPAT Model and Ridge Regression
}

\author{
Chunzheng Tian', Peng Li ${ }^{1}$, Hengyang Shao ${ }^{2 *}$, Meng Li ${ }^{1}$, Yongle Zheng ${ }^{1}$ \\ ${ }^{1}$ State Grid Henan Economic Research Institute, Zhengzhou, Henan Province, China \\ ${ }^{2}$ Department of Economics and Management, North China Electric Power University, \\ Baoding, Hebei, China
}

Received: 17 December 2018

Accepted: 8 May 2019

\begin{abstract}
The main objective of this paper was to analyze the status quo of energy consumption in rural Henan and identify the driving forces governing energy consumption based on the STIRPAT model. Potential driven factors of energy consumption including power of agricultural machinery, effective irrigated area, investment, income, total value, and per capital living space were selected to build the extended stochastic impacts by regression on population, affluence, and technology (STIRPAT) model, where ridge regression was applied to eliminate multicollinearity. The estimation results show that all the factors are positively related to rural energy consumption in Henan. The effective irrigated area is the maximal driven factor of energy consumption in rural Henan. Per capital living space, peasant household investment, power of agricultural machinery, total value of agricultural output, and per capita income all contribute to rural energy consumption growth in Henan. Finally, we propose policies that can be applied to mitigate future energy consumption in rural Henan.
\end{abstract}

Keywords: energy consumption, rural Henan, STIRPAT method, ridge regression

\section{Introduction}

Since the start of economic reform in 1979, China's rural economy has undergone high-speed development. Owing to the increase of resident income and the desire to improve living standards, rural reidents have an enormous demend for energy consumptions. Household consumption generates large amounts of greenhouse gases due to unsustainable consumption of lots of fossil-fuel energy. Agriculture production is also a major source of $\mathrm{CO}_{2}, \mathrm{~N}_{2} \mathrm{O}$, and $\mathrm{CH}_{4}$ [1]. Rapid rural development has become a vital factor contributing to global warming and climate change. So rural energy consumption has aroused public concerns about the environment and health [2, 3].

Henan Province, located in central China, is the most populous province in China (population 95.5 million and rural population of 54 million in 2017) with significant food and agricultural production. A large rural population means the huge potential of energy consumption in rural Henan. Therefore, Henan also generates a lot of carbon emissions in rural areas. 
[4] found that the total carbon emissions in Henan Province increased more than $25.00 \%$ between 2006 and 2015, and the primary sector had higher emissions in the southeast. Further study on how rural energy consumption has evolved in Henan will be of great significance in formulating future policies. Thus, investigating the driving forces governing rural energy consumption is of vital importance.

The remaining parts of our paper are organized as follows: Section 2 briefly reviews the existing literature while Section 3 describes the applied method and presents the economic models. Section 4 provides data sources and description and Section 5 discusses the results of the empirical analysis, followed by the conclusions and policy suggestions in Section 6.

\section{Literature Review}

Much of the literature has extensively studied $\mathrm{CO}_{2}$ emissions and energy consumption in China. The methods used to research $\mathrm{CO}_{2}$ emissions and energy consumption are as follows. [5] used the LMDI (logarithmic mean divisia index) method to study the potential factors influencing the growth of electricity consumption in China's industrial sector during 19982007. Similarly, [6] adopted the LMDI method to investigate factors that influence carbon emissions due to energy consumption based on different stages and sectors in China. Applying the Johansen co-integration methodology, [7] figured the energy consumption of China's commercial sector from 1981 to 2012 and estimated the energy conservation potentials. [8] applied data envelopment analysis (DEA) models to make an assessment of and optimize energy consumption in industrial sectors. Based on the stochastic impacts by regression on population, affluence, and technology (STIRPAT) model, [9] estimated the driving factors of urban household energy consumption in China. [10] applied the nonparametric additive regression models to examine the key influencing factors of $\mathrm{CO}_{2}$ emissions in China's transport sector. Applying the concept and methods of cointegration and Granger causality, [11] explored the relationship between energy consumption and economic growth in Vietnam. [12-14] adopted an integrated decomposition approach, including IDA (integrated decomposition analysis), SDA (structural decomposition analysis), and PDA (productiontheoretical decomposition analysis) to research energy consumption and carbon dioxide emissions in China.

Investigating the major driving factors of energy consumption is important to the formulation of energy conservation and emission reduction policies in rural areas. However, existing studies on the energy consumption of the rural areas are insufficient. Besides, studies on rural China are also very limited. Using a nonseparable household model, [15] studied energy consumption in rural Jangxi Province and specified the determinants of rural energy demand, forecasted future energy consumption and estimated the energy conservation potentials. Based on a village energy survey, [16] explored energy consumption in China's rural areas. Based on the improved grouped principal component method, [17] explored the progress of rural household energy sustainable development in China. Given this, we introduce the STIRPAT and ridge regression methods to investigate the main influencing factors of energy consumption in rural Henan Province. In addition, based on the actual situation of rural Henan, this paper identifies the major driving factors of rural energy consumption in Henan and proposes some policy recommendations.

Our paper is distinctive from other investigations for the following reasons. First, most investigations apply the conventional linear methods to study energy consumption and approximately ignore the multicollinearity between variables. The ridge regression in this paper can effectively eliminate multicollinearity to avoid pseudo-regression. Second, this study uses peasant household investment as an influencing factor to study energy consumption in rural Henan. This paper indicates that peasant household investment is also a major driver of energy consumption in rural Henan.

\section{Methodology}

\section{STIRPAT Model Construction}

The IPAT identity ( $I=P A T$; Eq. (1)) is often used as a basis for investigating the role of the various factors driving environmental pollution [18]:

$$
I=P . A . T
$$

...where $I$ represents impact (typically measured in terms of the emission level of a pollutant), $P$ denotes the size of the population, $A$ represents a country's affluence and $T$ is a technical index. In order to fully examine the factors

Table 1. Definition of all relevant variables used in the study. Source: Data used in this paper are obtained from the Henan Province Statistical Yearbook (2001-2016) and the China Statistical Yearbook (2001-20).

\begin{tabular}{|c|c|c|}
\hline Variable & Definition & $\begin{array}{c}\text { Units of } \\
\text { measurement }\end{array}$ \\
\hline E & $\begin{array}{c}\text { Total energy consumption in rural } \\
\text { Henan Province }\end{array}$ & $10^{4} \mathrm{t}$ \\
\hline PAM & $\begin{array}{c}\text { Total Power of Agricultural } \\
\text { Machinery }\end{array}$ & $10^{4} \mathrm{kw}$ \\
\hline EIA & Effective Irrigated Area & $10^{3}$ hectares \\
\hline PHI & Peasant Households Investment & $10^{8}$ Yuan \\
\hline PI & $\begin{array}{c}\text { Per capita income of Rural } \\
\text { Household }\end{array}$ & Yuan \\
\hline V & Total value of agricultural output & $10^{8}$ Yuan \\
\hline PS & Per Capital living space & Sq.m. \\
\hline
\end{tabular}


affecting environmental change, the IPAT model is too simple and has its limitations. Thus, using this model as a basis, Dietz and Rosa [19] proposed the STIRPAT model as follows:

$$
I_{t}=a P_{t}^{b} A_{t}^{c} T_{t}^{d} \xi_{t}
$$

...where $a$ represents the intercept term; $P, A$, and $T$ are the same as in Eq. (4); $b, c$, and $d$ represent the elasticities of environmental impacts with respect to $P, A$ and $T$ respectively; $e_{t}$ is the random disturbance; and subscript $t$ denotes the year as it is an annual data analysis. The STIRPAT model has been applied to analyze the influences of impacting factors of environmental pollution [20]. In order to eliminate possible heteroscedasticity, all variables take logarithmic form.

The sample data set is the time-series data of Henan province; therefore, Eq. (2) can be written as:

$$
L I_{t}=L a+b\left(L P_{t}\right)+c\left(L A_{t}\right)+d\left(L T_{t}\right)+\xi_{t}
$$

...where $P$ represents population size (104 persons), $A$ is measured by the per capita GDP (yuan), and $T$ is a technology index measured by energy efficiency (energy consumption in the ISI/its physical output-ENE).

To further our investigation, we rewrite and expand the STIRPAT model by incorporating the power of agricultural machinery, effective irrigated area, investment, income, total value, and per capital living space into the model base on specific situations in Henan. First, agriculture in Henan is undergoing rapid development [21]. Increasing agricultural output requires amounts of investment in agricultural machinery. Consequently, we introduce "power of agricultural machinery," "total value of agricultural output" and "peasant household investment" into the model. Secondly, Henan possesses amounts of agricultural land [22]. Hence, "effective irrigated area" is introduced into the model. Finally, with more income, rural residents have an enormous demand for household appliances, private cars and more housing space, which consumes massive amounts of energy to build houses and operate more household appliances [23]. So "per capita income" and "per capital living space" are also introduced to the model.

Based on the STIRPAT model and above analysis, we establish the econometric model of energy consumption in rural Henan province and Eq. (3) as follows:

$$
\begin{aligned}
L E_{t}= & L a+\beta_{1} L P A M_{t}+\beta_{2} L E I A_{t}+\beta_{3} L P H I_{t}+ \\
& +\beta_{4} L P I_{t}+\beta_{5} L V_{t}+\beta_{6} L P S_{t}+\xi_{t}
\end{aligned}
$$

...where E represents energy consumption in rural Henan (104 t), PAM denotes total power of agricultural machinery, EIA represents effective irrigated area, $P H I$ denotes peasant household investment, $P I$ indicates per capita income of rural households, $V$ represents total value of agricultural output, and PS indicates per capital living space.

\section{Ridge Regression}

Owing to interaction terms of the input variables in Equation (4), the model is likely to undergo severe multicollinearity - a common statistical phenomenon in which two or more predictor variables in a multiple regression model are highly correlated. Consequently, this violates a basic indispensable condition for OLS (ordinary least squares) to be unbiased. Coefficient estimates for the models described in linear regression depend on the independence of the model terms. When model terms are correlated and the columns of the design matrix $X$ have an approximate linear dependence, the matrix $\left(X^{T} X\right)^{-1}$ will become close to singular. As a result, the least-squares estimate [24] becomes significantly sensitive to random errors in the observed response $\mathrm{Y}$, which will generate a large variance.

$$
\hat{\beta}=\left(X^{T} X\right)^{-1} X^{T} Y
$$

This situation of multicollinearity can arise, for example, when data are collected without an experimental design. A solution to the problem of multicollinearity is to abandon the usual least-squares procedure and resort to biased estimation techniques. In using a biased estimation procedure, one is essentially willing to allow for a certain amount of bias in the estimates in order to reduce their variances. The ridge regression is one of the biased estimation adopted for this purpose, which was proposed by [25]. Ridge regression estimates are given by

$$
\hat{\beta}=\left(X^{T} X+k I\right)^{-1} X^{T} y, k>0
$$

...where $\mathrm{k}$ is the biasing parameter or ridge parameter which satisfies $k>0$, and $X$ is the independent variable matrix. $I$ is unit matrix, and $Y$ is the dependent variable vector. Generally, the ridge regression estimates are computed for various increasing values of $\mathrm{k}$, from $k=0$, until an optimum value of $k$ is determined for which all the regression coefficients appear to have stabilized. However, it is worth examining the ridge solution for a range of admissible values of $k$. Small positive values of $k$ will ameliorate the conditioning of the problem and abate the variance of the estimates. While biased, the reduced variance of ridge regression estimates usually results in a smaller mean square error when compared to least-squares estimates. In the econometric field, several methods of acquiring the optimal value of the ridge parameter have been proposed. This study uses the ridge trace plot method, which is the most popular in the econometric literature. By plotting the values of the coefficients against the successive values of $k$, a curve referred to as the ridge trace is obtained. Coefficients are estimated with various levels of $k$ from zero to one. 
Table 2. Statistical description of all variables in the econometric model.

\begin{tabular}{|c|c|c|c|c|c|}
\hline Variable & Units of measurement & Mean & Std. dev. & Min & Max \\
\hline E & $104 \mathrm{t}$ & 1538.543 & 440.0965 & 995.71 & 2153.11 \\
\hline PAM & $104 \mathrm{kw}$ & 9193.159 & 1806.371 & 6078.7 & 12032.36 \\
\hline EIA & 103 hectares & 5009.547 & 185.6581 & 4766 & 5360.3 \\
\hline PHI & 108 Yuan & 612.1219 & 218.0179 & 276.13 & 899.39 \\
\hline PI & Yuan & 5561.909 & 3256.108 & 2097 & 11697 \\
\hline V & 108 Yuan & 4896.966 & 2098.948 & 2102.79 & 7799.67 \\
\hline PS & Sq.m & 34.79 & 6.069517 & 27.03 & 46.65 \\
\hline
\end{tabular}
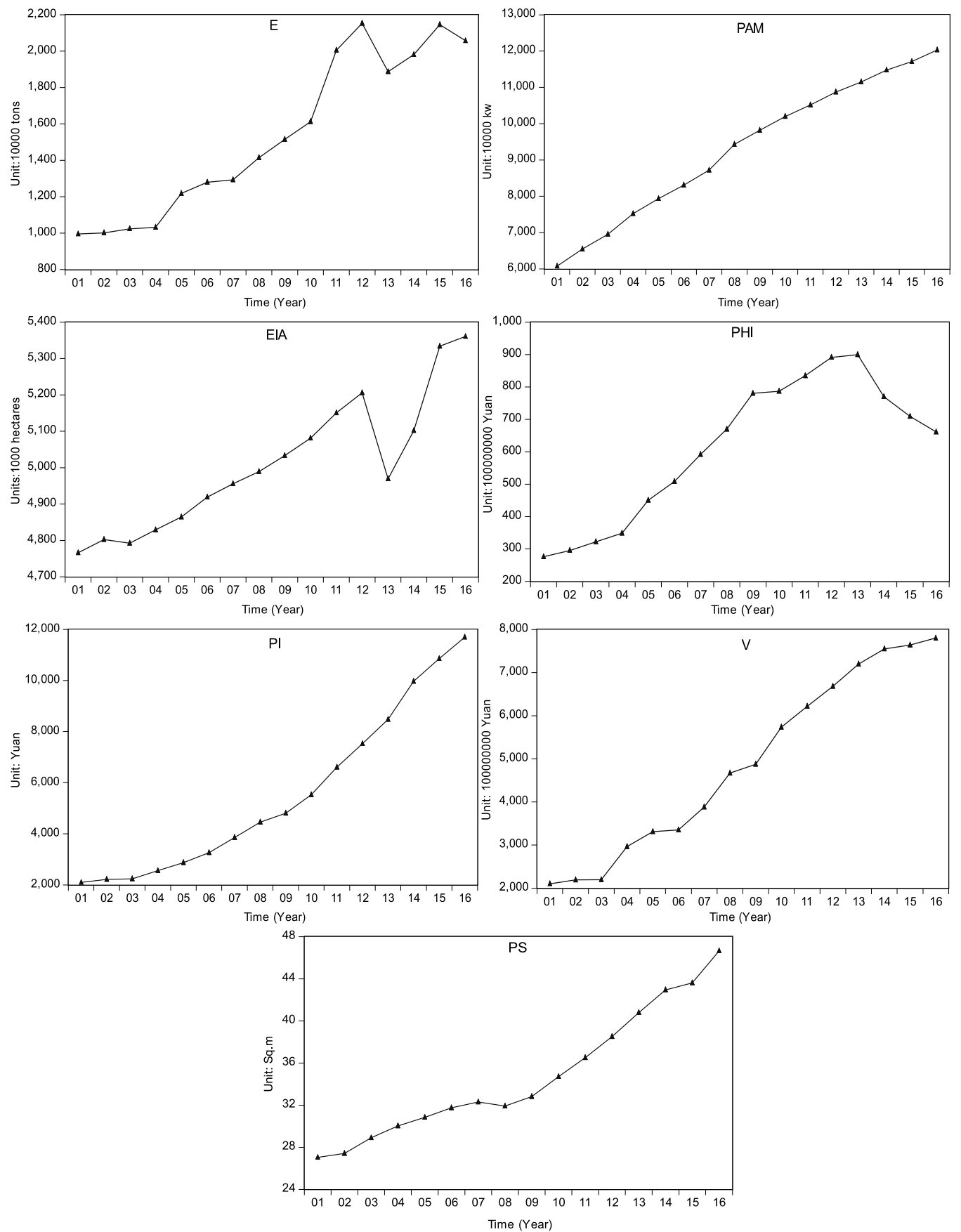

Fig. 1. Trends of energy consumption, power of agricultural machinery, effective irrigated area, investment, income, total value, and per capital living space during 2001-2016. 
The $\hat{\beta}$ coefficients are then plotted with respect to the values of $k$ and the optimal value of $k$ is chosen at the point where the $\hat{\beta}$ coefficients seem to stabilize.

\section{Data Source and Description}

The time-series data set of Henan covers the period 2001-2016. All the data are collected from the Henan Province Statistical Yearbooks (2001-2016) and the China Statistical Yearbooks (2001-2016). Based on the quantity of various types of fossil fuels and electricity consumption and their TCE factors from the 2006 IPCC reports and China's National Development and Reform Commission (2007), we computed rural Henan energy consumption. The definitions of the variables are shown in Table 1, while Table 2 shows the statistical description of all the variables in the econometric model. Based on the annual data of the independent and dependent variables, Fig. 1 demonstrates the relative changes in energy consumption, power of agricultural machinery, effective irrigated area, investment, income, total value, and per capital living space during 2001-2016.

\section{Empirical Results}

In this section the main findings of the research are presented. The section begins with the multicollinearity test. Section 5.1 provides the results of the multicollinearity test and OLS regression. Section 5.2 implements the ridge regression. The analysis and discussion of the results are arranged in Section 5.3.

\section{Multicollinearity Test}

For all of the independent variables, the multicollinearity test should be adopted to demonstrate the drawback of OLS. Actually, the power of agricultural machinery, investment, income, total value, and per capital living space would increase accordingly with agricultural economic development and social progress. Based on the results shown in Tables 3 and 4 , the correlations of more than half of the variables including power of agricultural machinery, investment, income, total value, and per capital living space - are
Table 4. Results of OLS regression.

\begin{tabular}{|c|c|c|c|}
\hline OLS result & $\begin{array}{c}\text { Unstandardized } \\
\text { coefficient }\end{array}$ & $\begin{array}{c}\text { t-Statistic } \\
\text { Sig. }\end{array}$ & VIF \\
\hline Constant & -13.214 & 0.105 & \\
\hline $\operatorname{lnPAM}$ & -1.790 & 0.023 & 133.725 \\
\hline $\operatorname{lnEIA}$ & 3.104 & 0.014 & 9.217 \\
\hline $\operatorname{lnPHI}$ & 0.582 & 0.009 & 34.595 \\
\hline $\ln \mathrm{PI}$ & 0.122 & 0.610 & 125.312 \\
\hline $\ln \mathrm{V}$ & 0.218 & 0.486 & 132.827 \\
\hline $\operatorname{lnPS}$ & 1.087 & 0.121 & 75.874 \\
\hline Adjusted $\mathrm{R}^{2}$ & 0.973 & & \\
\hline $\begin{array}{c}\text { F-statistic } \\
\text { Sig. }\end{array}$ & 0.000 & & \\
\hline
\end{tabular}

high, and the VIF values (one of the most common criteria [26]), of the power of agricultural machinery, income, total value, per capital living space, and investment are much higher than 10. That is to say, serious multicollinearity exists between these variables. Due to the possible interaction between variables, their marginal influence cannot be reflected by the regression coefficients obtained through OLS.

\section{Ridge Regression Estimation}

The ridge regression method adopted here in forming the multiple linear regression model is to avoid the limitations of OLS. The validity of the ridge regression model proposed can be verified by reliable indicators such as adjusted $\mathrm{R}^{2}$, F-test, and t-test. Table 4 demonstrates that the regression equation is significant (F-statistic Sig.<0.05) and the fitting degree (adj. $\mathrm{R}^{2}=0.973$ ) is excellent. However, half independent variables are not significant (t-Statistic Sig. $>0.05$ ).

The ridge regression is adopted to estimate the coefficients in the STIRPAT model. According to the ridge regression, Eq. (6), Fig. 2, and Fig. 3 respectively illustrate ridge trace and the relationship between $\mathrm{R}^{2}$ and $k$. To clearly demonstrate the change of regression coefficients and determine the least $\mathrm{k}$ value, only 22 points in each group have been drawn in Fig. 2

Table 3. Results of correlation test.

\begin{tabular}{|c|c|c|c|c|c|c|}
\hline & $\ln \mathrm{PAM}$ & $\operatorname{lnEIA}$ & $\ln \mathrm{PHI}$ & $\ln P I$ & $\ln \mathrm{V}$ & $\operatorname{lnPS}$ \\
\hline $\operatorname{lnPAM}$ & 1 & & & & & \\
\hline $\operatorname{lnEIA}$ & $0.904 * *$ & 1 & & & & \\
\hline $\ln \mathrm{PHI}$ & $0.932 * *$ & $0.769 * *$ & 1 & & & \\
\hline $\operatorname{lnPI}$ & $0.973 * *$ & $0.921 * *$ & $0.856^{* *}$ & 1 & & \\
\hline $\ln V$ & $0.992 * *$ & $0.898 * *$ & $0.927 * *$ & $0.980 * *$ & 1 & \\
\hline $\ln \mathrm{PS}$ & $0.941 * *$ & $0.897 * *$ & $0.776^{* *}$ & $0.981 * *$ & $0.944 * *$ & 1 \\
\hline
\end{tabular}


because all the coefficients maintain a stable trend when $\mathrm{k}$ increases from 0.2 to 1 . The standardized regression coefficients of each independent variable change quickly at first with the increase of $\mathrm{k}$ value and then sharply turn to be stable after $\mathrm{k}=0.12$. Fig. 3 demonstrates that the $\mathrm{R}^{2}$ of ridge regression changes with a high change rate before $\mathrm{k}=0.12$, and the rate becomes much lower from the $\mathrm{k}$ value of 0.12 . Consequently, the smallest value of $\mathrm{k}(\mathrm{k}=0.12)$ can be performed with a high adjusted $\mathrm{R}^{2}$ of 0.941 . Thus, it is reasonable to choose $\mathrm{k}=0.12$ in this paper considering good interpretability.

The F test can be passed with the result of F Sig. $($ Sig. $=0.0000049<0.05)$, which means that there is a linear relationship between independent and dependent variables. Meanwhile, the constant term and the regression coefficient's $t$ Sig. of each independent

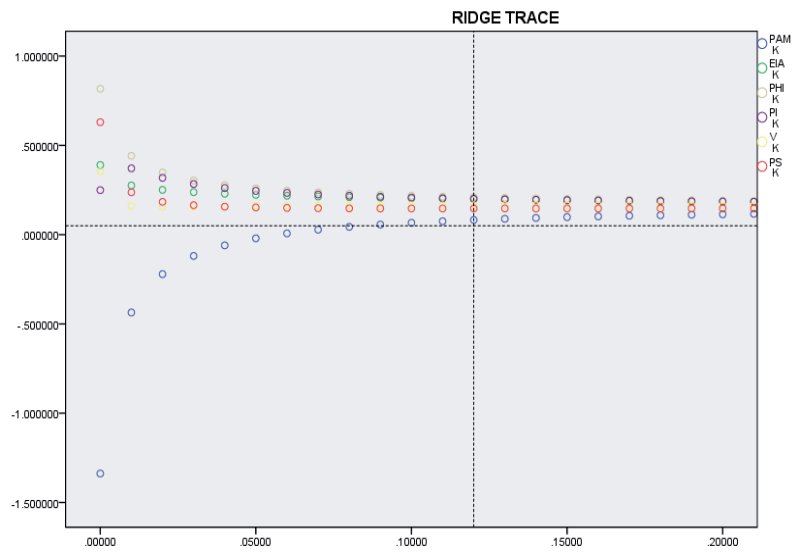

Fig. 2. Curves of ridge trace.

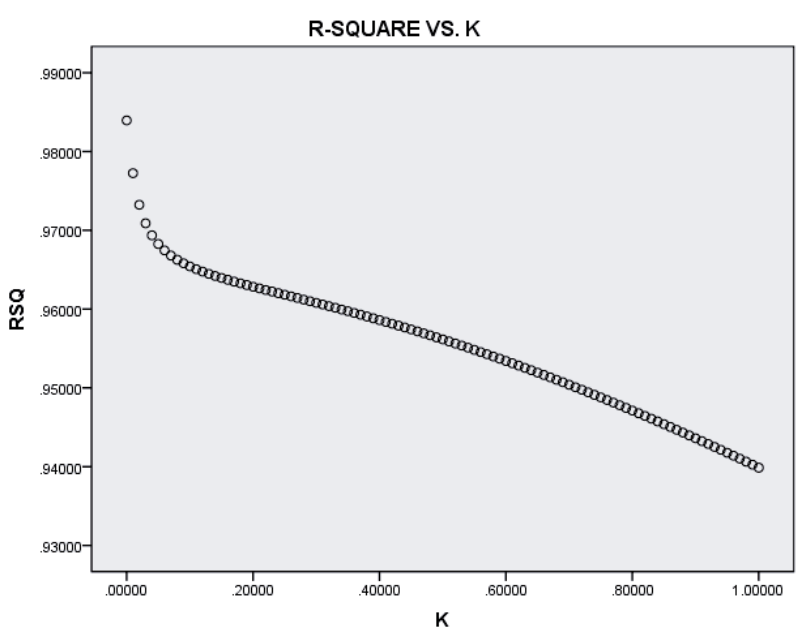

Fig. 3. Changes of $\mathrm{k}$ under different RSQ. variable can also satisfy the requirement $(<0.1)$, which indicates that all of the independent variables should be introduced into the regression equation. The details of the data involved are presented in Table 5.

Eventually, the fitted ridge regression equation is as follows:

$$
\begin{gathered}
\ln E=-10.736+0.11 \ln P A M+1.586 \ln E I A+0.149 \ln P H I+ \\
+0.098 \ln P I+0.101 \ln V+0.252 \ln P S
\end{gathered}
$$

\section{Analysis of Results of Ridge Regression}

Table 5 provides the estimated results of the linear effects of the driving forces of energy consumption in ridge regression. It can be seen that all the estimated coefficients are statistically significant at the level of $1 \%, 5 \%$ or $10 \%$ (Eq. (7)).

The elasticity of effective irrigated area is greatest (1.586), indicating that a $1 \%$ increase in effective irrigated area would lead to a $1.586 \%$ increase in energy consumption when other factors remain constant. This means that an effective irrigated area is positively related to energy consumption in rural Henan. The estimate results conform to the official statistics, which show that the effective irrigated area is primarily responsible for energy consumption growth in rural Henan.

The elasticity of per capital living space is 0.252 , indicating that a $1 \%$ increase in per capita living space would lead to a $0.252 \%$ increase in energy consumption when other factors remain constant. This means that the surge in per capita living space leads to a rapid increase in energy consumption in rural Henan. The estimated results are supported by Henan government statistics, which reveal that per capita living space is a major contributor to energy consumption increase in rural Henan.

Peasant household investment passes the t-test with elasticity of 0.149 , just below the effective irrigated area and per capita living space. This means that peasant household investment is also a major driver of energy consumption in rural Henan. The estimated result is supported by (Hao et al., 2018) [27], whose research results reveal that investment is also a major contributor to energy consumption increase in China's rural area.

The elasticities of total value of agricultural output and per capita income of rural household on energy consumption are respectively significant and positive $(0.101 \%, 0.098 \%)$. The remarkable positive signs of agricultural output and per capita income indicate

Table 5. Results of tests for each independent variable and constant.

\begin{tabular}{|c|c|c|c|c|c|c|c|}
\hline & Constant & $\operatorname{lnPAM}$ & $\operatorname{lnEIA}$ & $\operatorname{lnPHI}$ & $\operatorname{lnPI}$ & $\operatorname{lnV}$ & $\ln \mathrm{VS}$ \\
\hline Coefficient's t Sig & $-10.736^{*}$ & $0.110^{*}$ & $1.586^{* *}$ & $0.149^{* *}$ & $0.098^{* * *}$ & $0.101^{* * *}$ & $0.252^{* *}$ \\
\hline
\end{tabular}

Note: $* * *$ significant at $1 \%, * *$ significant at $5 \%,{ }^{*}$ significant at $10 \%$ 
that more agricultural output and income are inclined to increase energy consumption (Zhang et al., 2012) [28].

\section{Conclusions and Policy Implications}

Using the time-series data of rural Henan during 2001-2016, this paper explores the driving forces of energy consumption in rural Henan with the STIRPAT and ridge regression models. The results show that the linear effect of effective irrigated area is a positive pattern and effective irrigated area is a maximal influencing factor due to rural energy consumption relying mainly on agricultural production, which is closely related to the effective irrigated area. Per capita living space also follows a positive pattern in relation to energy consumption because the expanding living space means large demand for household appliances and building materials that consume a large amount of energy. The impact of peasant household investment exhibits a positive elasticity of 0.149 , since more investment in agricultural infrastructure and breeding industry also is a major reason for the increase of energy consumption. Total power of agricultural machinery is positively related to energy consumption due to more agricultural machines having much greater demand for electricity, diesel and gasoline. Total value of agricultural output and per capita income of rural areas also augment energy consumption, since economically developed rural areas are more likely to choose commercial energy such as electricity, natural gas or LPG.

The above results have significant policy implications.

First, optimizing farmland management and introducing advanced irrigation technologies. As for the effective irrigated area identified as the maximal influencing factor, Henan should implement targeted land measures to abate energy consumption. On the one hand, the Henan government should centralize the cultivated land for unified management according to local conditions, which facilitates concentrated irrigation, cultivation and harvest. On the other hand, energy-saving irrigation technology research and development should be further strengthened. The government should encourage farmers to use drip and spray irrigation techniques to replace flood irrigation through government subsidies.

Secondly, promoting the use of energy-saving building materials and household appliances. The government should prohibit the damage to farm land for brick-making, and ban the production and use of solid clay brick. Meanwhile, green and energy-saving building materials should be vigorously advocated for building houses. In order to promote household energy efficiency and abate energy consumption, the Henan government must strongly encourage farmers to use green and energy-saving household appliances through the government's subsidy program for rural appliance purchases.

Thirdly, promoting the employment of clean energy. In less-developed rural areas, farmers using traditional biomass energy, including firewood, straw, animal dung and other crop residues account for a major source of household energy consumption. Consequently, the government should advocate for farmers investing in clean energy such as electricity and solar. The scientific and standardized breeding industry also should be promoted, which can recycle biomass energy. In the meantime the government should increase R\&D efforts on traditional biomass energies and change them into energies as efficient, clean and convenient as commodity energies.

Fourthly, unifying management of agricultural machinery and the use of new energy agricultural machinery with higher energy efficiency. The government should encourage farmers to reduce the use of agricultural machinery consuming diesel or gasoline. Unified management of agricultural machinery is conducive to reducing energy consumption. In the meantime, the hybrid, low-energy and electric agricultural machinery should be further promoted, and the purchase and use of electric and agricultural machinery should be subsidized.

Finally, changing energy consumption habits and augmenting the use of clean energy. Relevant policies should be launched to encourage farmers to use clean energy according to local conditions, such as electricity, solar and wind. Moreover, farmers should be encouraged to reduce the use of private cars and motorcycles consuming gasoline and promote the use of hybrid, low-energy and electric vehicles. In the long run, given that the margin of improving automobile engine and refining technology is limited, the R\&D of electric vehicle technology should be strengthened, and the purchase and use of electric and hybrid vehicles should be subsidized.

However, there are some limitations to this study. Firstly, there are significant differences in the distribution of natural resources and economic development in rural Henan due to its vast land area. At the same time, the power of agricultural machinery, effective irrigated area, investment, income, total value, and per capital living space also vary in different regions. Hence, rural Henan energy consumption is affected by regional characteristics, whether on the average level or on the overall level. This study investigates the influencing factor of energy consumption from a provincial perspective and ignores regional heterogeneity. Taking this issue into account, we will investigate the factors driving energy consumption from a regional perspective in future research.

\section{Conflict of Interest}

The authors declare no conflict of interest. 


\section{References}

1. PRATT C., REDDING M.R., HILL J., GUIEYSSE B. Good science for improving policy: greenhouse gas emissions from agricultural manures. Animal Production Science. 55 (6), 691, 2015.

2. HAN H., WU S. Rural Residential Energy Transition and Energy Consumption Intensity in China. Energy Economics, p. S0140988318301580, 2018.

3. REZAEI R., GHOFRANFARID M. Rural households' renewable energy usage intention in Iran: Extending the unified theory of acceptance and use of technology. Renewable Energy, 122, 382, 2018.

4. HE J., ZHANG P. Evaluating the Coordination of Industrial-Economic Development Based on Anthropogenic Carbon Emissions in Henan Province, China. International Journal of Environmental Research and Public Health, 15 (9), 2018

5. WANG F., D B.M., Y X.P., A C. China's structural change: A new SDA model. Economic Modelling. 43, 256, 2014.

6. XU S.C., H Z.X., L R.Y. Factors that influence carbon emissions due to energy consumption based on different stages and sectors in China. Journal of Cleaner Production. 115, 139, 2016.

7. LIN B.Q., W A.L. Estimating energy conservation potential in China's commercial sector. Energy. 82, 147, 2015.

8. OLANREWAJU O.A., JIMOH A.A., KHOLOPANE P.A. Integrated IDA-ANN-DEA for assessment and optimization of energy consumption in industrial sectors. Energy. 46 (1), 629, 2012.

9. LIU M.Z., L X.X., MANAGEMENT S.O. Study on the influencing factors of urban household energy consumption in china based on stirpat model. Resources \& Environment in the Yangtze Basin, 2017.

10. XU B., LIN B.Q. Factors affecting $\mathrm{CO}_{2}$ emissions in China's transport sector: a dynamic nonparametric additive regression model. Journal of Cleaner Production. 101, 311, 2015.

11. TANG C.F., TAN B.W., OZTURK I. Energy consumption and economic growth in Vietnam. Renewable \& Sustainable Energy Reviews. 54 (11), 1506, 2016.

12. LIU X., ZHOU D., ZHOU P., WANG Q. Factors driving energy consumption in China: A joint decomposition approach. Journal of Cleaner Production, 172, 724, 2018

13. WANG Q., HANG Y., SU B., ZHOU P. Contributions to sector-level carbon intensity change: an integrated decomposition analysis. Energy Economics, 70, 12, 2018.
14. WANG Q., C Y-H., C C-R. Driving factors behind carbon dioxide emissions in China: A modified productiontheoretical decomposition analysis. Energy Economics, 51, $252,2015$.

15. LE C., HEERINK N., BERG M.V.D. Energy consumption in rural China: a household model for three villages in Jiangxi Province. Ecological Economics. 58 (2), 407, 2006.

16. WANG R., JIANG Z. Energy consumption in China's rural areas: A study based on the village energy survey. Journal of Cleaner Production. 143, 452, 2017.

17. ZHANG M., SU B. Assessing China's rural household energy sustainable development using improved grouped principal component method. Energy. 113, 509, 2016.

18. XU B., LIN B.Q. Reducing $\mathrm{CO}_{2}$ emissions in China's manufacturing industry: Evidence from nonparametric additive regression models. Energy. 101, 161, 2016.

19. DIETZ T., ROSA E.A. Effects of Population and Affluence on $\mathrm{CO} 2$ Emissions. Proceedings of the National Academy of Sciences of the United States of America. 94 (1), 175, 1997.

20. XU B., LIN B.Q. A quantile regression analysis of China's provincial $\mathrm{CO}_{2}$ emissions: Where does the difference lie? Energy Policy. 98, 328, 2016.

21. SU M., JIANG R., LI R.R. Investigating Low-Carbon Agriculture: Case Study of China's Henan Province. Sustainability. 9 (12), 2295, 2017.

22. XING, W., WANG, W., SHAO, Q., DING, Y. Estimating net irrigation requirements of winter wheat across central-eastern china under present and future climate scenarios. Journal of Irrigation and Drainage Engineering, 144 (7), 05018005, 2018.

23. LIU C., LIN B. Evaluating Design of Increasing Block Tariffs for Residential Natural Gas in China: A Case Study of Henan Province. Computational Economics, 52 (1), 1, 2017.

24. KUTNER., MICHAEL H. Applied linear statistical models 4ed: McGraw-Hill Irwin. 342, 2005.

25. HOERL A.E., KENNARD R.W. Ridge Regression: Biased Estimation for Nonorthogonal Problems. Technometrics. 12 (1), 55, 1970.

26. READ C.B., BELSLEY D.A. Condition Diagnostics, Collinearity and Weak Data in Regression. Biometrics. 50 (1), 1994.

27. HAO Y., W L.O., Z L.Y., Y M.J. The Dynamic Relationship between Energy Consumption, Investment and Economic Growth in China's Rural Area: New Evidence Based on Provincial Panel Data. Energy. 154, 2018.

28. ZHANG M., GUO F.Y. Analysis of rural residential commercial energy consumption in China. Energy. 52 (1), 222, 2013. 